\title{
SEISMIC BEHAVIOUR OF DIAPHRAGM ARCHES: CASE STUDIES FROM CATALAN GOTHIC CHURCHES
}

\author{
D. CACACE ${ }^{1}$, V. CORLITO ${ }^{1}$, M. ZIZI ${ }^{1}$, G. DE MATTEIS ${ }^{1 *}$ AND P. ROCA $^{2}$ \\ ${ }^{1}$ Department of Architecture and Industrial Design (DADI) \\ University of Campania "Luigi Vanvitelli" \\ San Lorenzo Abbey, 81030 Aversa, Italy \\ e-mails: \{daniela.cacace, valentina.corlito, mattia.zizi\}@unicampania.it \\ gianfranco.dematteis@unicampania.it (*corresponding author) \\ ${ }^{2}$ Department of Civil and Environmental Engineering \\ Universitat Politècnica de Catalunya \\ (UPC - Barcelona Tech), 08034 Barcelona, Spain \\ e-mail: pere.roca.fabregat@upc.edu
}

Keywords: Masonry Churches, Catalan Gothic, Diaphragm Arches, Seismic Behaviour, Linear Kinematic Analysis

\begin{abstract}
The Gothic style spread, starting from the $12^{\text {th }}$ century, from the Ile-de-France to England and other countries of the Mediterranean area, such as Spain and Italy, according to different configurations and construction techniques, influenced by economic, environmental and social factors. The so-called Catalan Gothic style is not exclusive to the architecture of the Principality of Catalonia but extends to the territories of the Crown of Aragon and Southern France. Its most important characteristics, based on the unitary conception of space and horizontality, had the religious architecture as their major reference. Among other structural elements, the large use of diaphragm arches, built transversally to the longitudinal direction of the nave, has been identified as peculiar both in ecclesiastic and civil Catalan Gothic architecture, although this technique is widely diffused also in the rest of the Mediterranean Europe. The present study focuses on the behaviour of this construction system under horizontal loads. After some brief notes on the history, origins and evolution of diaphragm arches, preliminary outcomes obtained by means of seismic analyses are provided in this paper. In particular, the possible collapse mechanisms of such remarkable curved structures have been firstly investigated by implementing FEM Models derived from real Catalan examples. Therefore, seismic analyses by means of analytical models have been carried out on the detected cases in order to demonstrate the capacity of this kind of structural skeleton, the importance of geometric ratios and the influence that specific typical elements may have in modifying the seismic behaviour of the analysed structures.
\end{abstract}

\section{INTRODUCTION}

During the first half of the $13^{\text {th }}$ century, a form of Gothic architecture different from that typical of the northern France and characterized by its own distinctive characters (deeply influenced by the Romanesque style) appeared in the central-southern France [1], spreading 
significantly in Mediterranean European countries.

The churches built according to the so-called Minor Gothic style were generally characterized by thicker proportions, with a large frequency of wide-span single naves, massive rib vaults and diaphragm arches [2].

Among other constructive features, the extensive use of diaphragm arches has been identified as peculiar not only in churches, but also in civil architecture [3,4]. These structural elements, probably derived from the Romanesque construction techniques of northern Italy and related to the Cistercians constructive rules and experimentations [1], made their first appearance in western Europe during the $11^{\text {th }}$ and early $12^{\text {th }}$ centuries, becoming a typical element of the Catalan Gothic architecture.

Different studies have been carried out in order to assess the origins and the evolution of diaphragm arches, as well as to understand the constructive methodology and the behaviour of such a structural skeleton [4-7]. Moreover, some researches [2, 8] specifically justify the structural differences detected in the Mediterranean Gothic buildings by considering the high seismic hazard of the territory in which they were realized and the need to modify the stone skeletons of the cathedrals because of stability reasons.

In this paper, the seismic behaviour of real examples of diaphragm arches present in the Catalan area has been investigated by means of an integrated numerical-analytical approach. Firstly, step-by-step numerical analyses, aimed at defining the possible position of the hinges in the kinematic chains, have been implemented with FEM Models and validated on the basis of studies found in literature. Secondly, and in order to prove the seismic capacity of such a
system, limit analyses with a kircmatic approach have been darried out, considering both the
original configuration of the detected arcades and the modified geometries obtained by
progressively removing parts of their specific constitutive elenents.
2 THE CATALAN GOTHIC

Register for freeneralhttps//www.scipedia.com to download the version without the watermark Catalan architecture features were introduced by Cistercian monks in the second half of the $12^{\text {th }}$ century, but a true diffusion of the style, as we understand it today, only occurred after the $14^{\text {th }}$ century. Several authors $[9,10]$ put Catalan Gothic architecture in relation with the cultural context of the Mediterranean Gothic, distancing it from the Gothic culture of Northern Europe, to which the Gothic style of many other areas of the Iberian Peninsula belongs. Indeed, this style is not exclusive of the architecture of the Principality, actually extending itself to all the territories of the Crown of Aragon: the kingdoms of Valencia, Mallorca - Rossellón included Naples and Sicily. According to the type of structural skeleton adopted in the various constructions, two different Gothic models can be identified in Spain [8]: the cathedrals that follow the typical French scheme and a different type (mainly diffused in Catalonia and Andalusia) inspired by the canons of the Mediterranean Gothic.

As far as the religious architecture is concerned, the essential characteristics of Catalan churches are the unitary conception of space and horizontality. Generally, the layouts contemplate the wide aisleless churches and, when the three-nave plan is considered, there is no transept and the side aisles are at almost the same height of the central nave [3]. The weight of the ribbed vaults is often carried by internal buttresses with chapels in the interstices, favouring compact exterior forms. 
Despite some differences, mainly related to the number of naves, the disposition and arrangement of buttresses, cross vaults and roofing systems, the extensive use of diaphragm arches can be identified as a peculiar element of this kind of churches.

From a structural point of view, the diaphragm arches act as horizontal bracing elements for the longitudinal walls, concentrating the load at specific points, in correspondence with the buttresses. Moreover, when these elements follow one another at closely spaced intervals, the nave assumes the function of support for the roof.

Obviously, the distance of the diaphragm arches and their geometric configuration influence the conformation of the other structural elements and, in particular, the characteristics of the adopted roofing system. As an instance, the typical use of terraced roofs in the Mediterranean Gothic structures is connected to the regular adoption of flat diaphragm arches along the entire length of the naves.

\subsection{Case studies}

Different developments of the diaphragm system (concerning also the arrangement of the buttresses) can be identified in the religious buildings belonging to the Mediterranean Gothic style.

In order to investigate the influence of the geometric parameters on the global behaviour of a specific transversal diaphragm, two different geometric coefficients are utilized. These coefficients characterize the relationship between the total height of the diaphragm and the rise of the nave arch at the

the nave arch and the to

In Tables 1 and Fig

cathedrals are shown an

analysed in the followin

Maria del Pi [SMP]
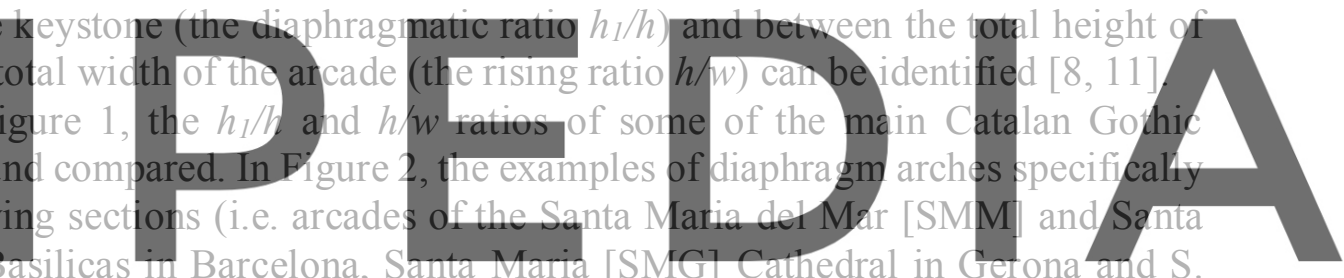

Joan Baptista [SJB] Cathedral in Perpignan) are provided.

Register for free at https//www.scipedia.com to download the version without the watermark

\begin{tabular}{llccc}
\hline Cathedrai/Basilica & Acronym & Layout & $\boldsymbol{h} 1 / \boldsymbol{h}$ & $\boldsymbol{h} / \boldsymbol{w}$ \\
\hline Santa Creu i Santa Eulàlia (Barcelona) & {$[\mathrm{SCE}]$} & Three-nave & 1.12 & 0.58 \\
\hline Santa Maria del Mar (Barcelona) & {$[\mathrm{SMM}]$} & Three-nave & 1.02 & 0.89 \\
\hline Santa Maria (Tortosa) & {$[\mathrm{SMT}]$} & Three-nave & 1.10 & 0.59 \\
\hline Santa Maria del Pi (Barcelona) & {$[\mathrm{SMP}]$} & One-nave & 1.07 & 0.97 \\
\hline Santa Maria (Gerona) & {$[\mathrm{SMG}]$} & One-nave & 1.03 & 1.04 \\
\hline S. Joan Baptista (Perpignan) & {$[\mathrm{SJB}]$} & One-nave & 1.11 & 0.79 \\
\hline Santa Maria De La Seu (Manresa) & {$[\mathrm{SMS}]$} & One-nave & 1.06 & 0.75 \\
\hline
\end{tabular}



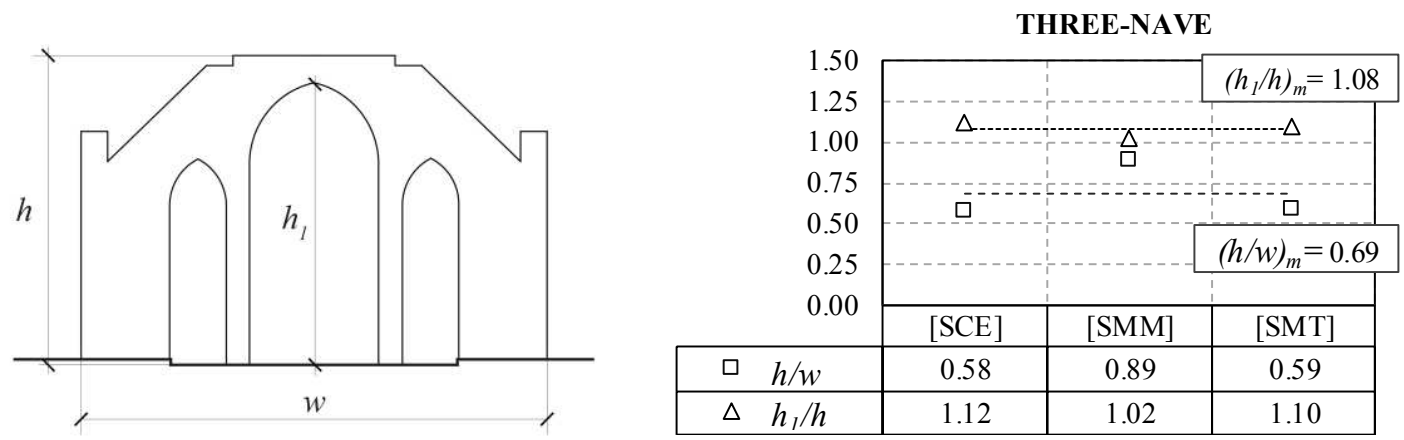

(a)
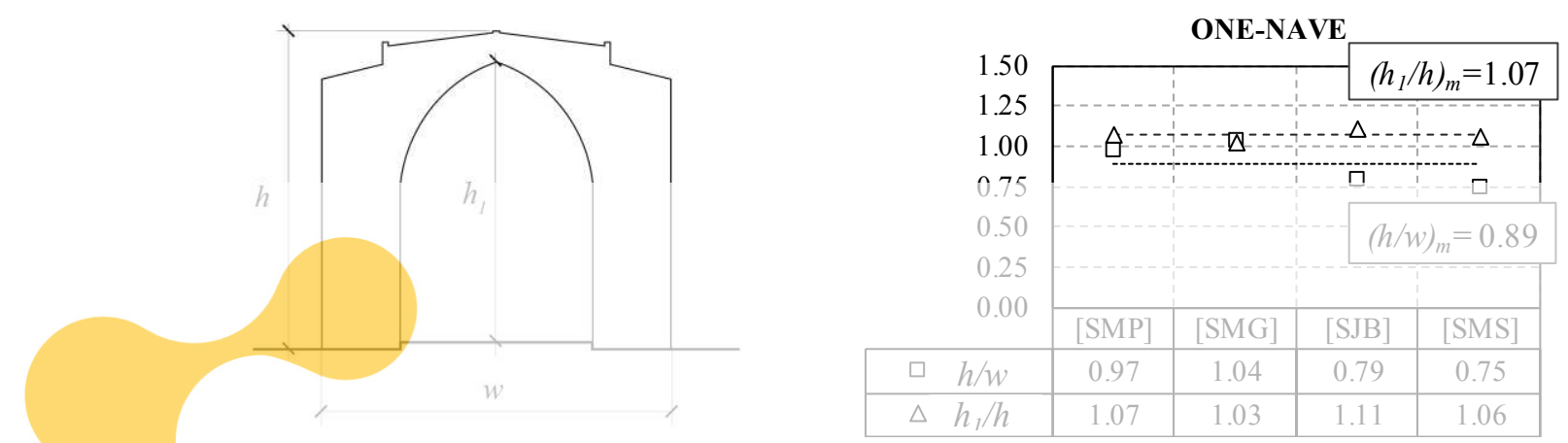

(b)

Figure 1: The $h_{I} / h$ and $h / w$ ratios for some of the main Catalan Gothic Cathedrals with (a) three-nave and (b)
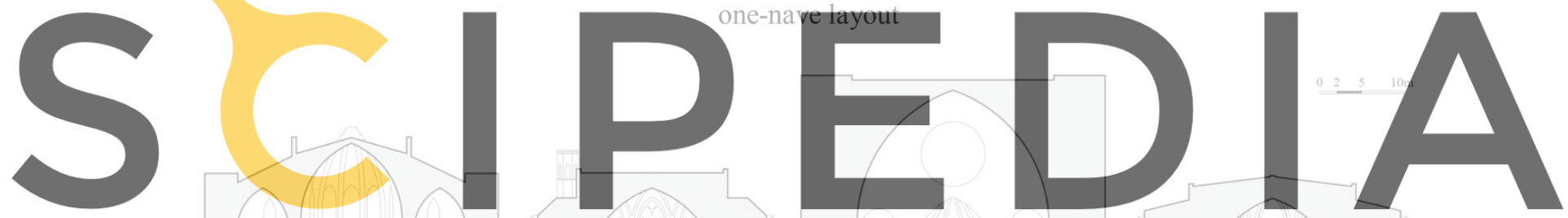

Register for free at https//www.scipedia.com to download the version without the watermark
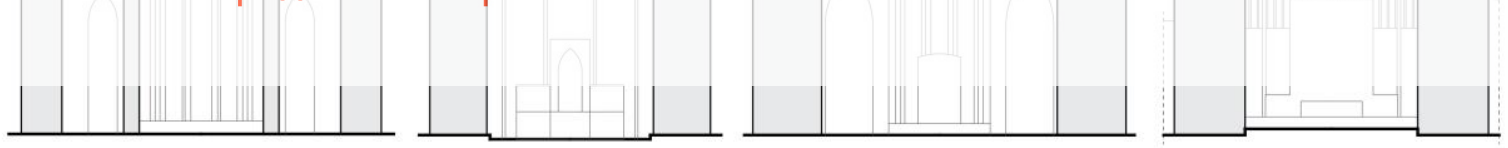

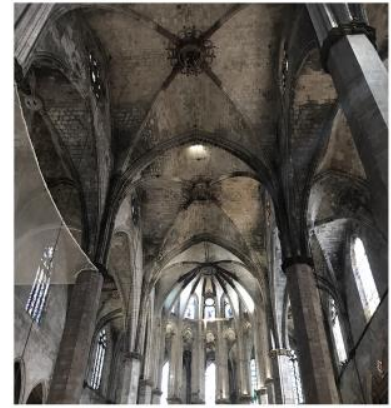

(a)

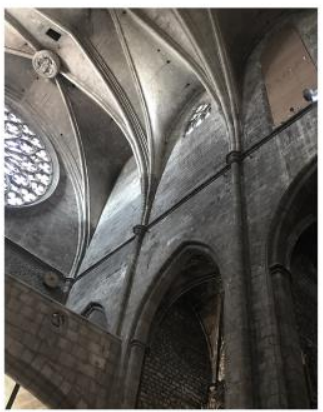

(b)

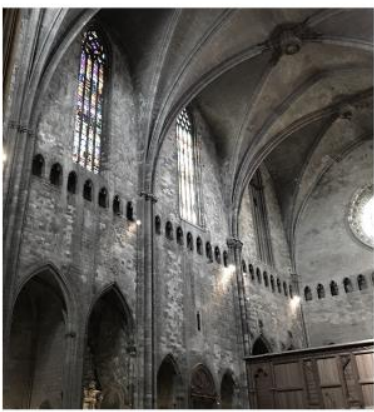

(c)

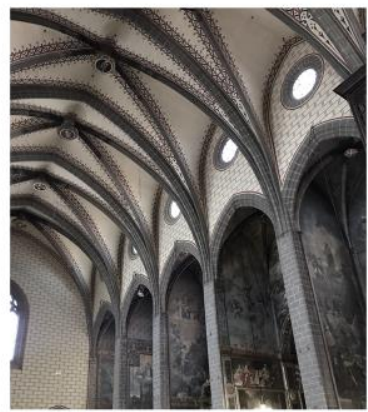

(d)

Figure 2: Section of the diaphragm arch and internal photographic survey for (a) Santa Maria del Mar [SMM] Basilica in Barcelona, (b) Santa Maria del Pi [SMP] Basilica in Barcelona, (c) Santa Maria [SMG] Cathedral in Gerona, (d) and S. Joan Baptista [SJB] Cathedral in Perpignan 


\section{THE LIMIT ANALYSIS WITH KINEMATIC APPROACH}

\subsection{General}

In the following, the seismic behaviour of the diaphragmatic system is investigated by means of limit analyses with a kinematic approach. The proposed approach is considered suitable for the purpose of this study, given the strict dependence of the results on the geometry of the structures, and considering the unavailability of specific mechanical characteristics for the investigated cases.

The limit analysis is based on the Heyman's [12] assumptions for the masonry behaviour, according to which: $i$. masonry has an infinite compressive strength; $i i$. masonry has zero tensile strength; iii. sliding failure in masonry cannot occur. Under these assumptions, a masonry element can be considered as an assembly of non-deformable blocks and its failure can be related to the formation of rotational hinges, which induce a displacement distribution into the structure (i.e. kinematic chain).

It is worth noticing that the identification of the position of the hinges is not an easy issue and is not enough for defining the subdivision in rigid blocks, which is influenced by the direction of the potential cracks, too.

The lability of the structure is the sufficient and necessary condition for defining the statically admissible kinematic mechanism. Once that the position of the hinges has been defined, the limit analysis with the kinematic approach provides the calculation of the load

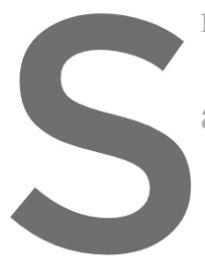
multiplier $\alpha$, by mean

\section{Since externál loads} assumed:
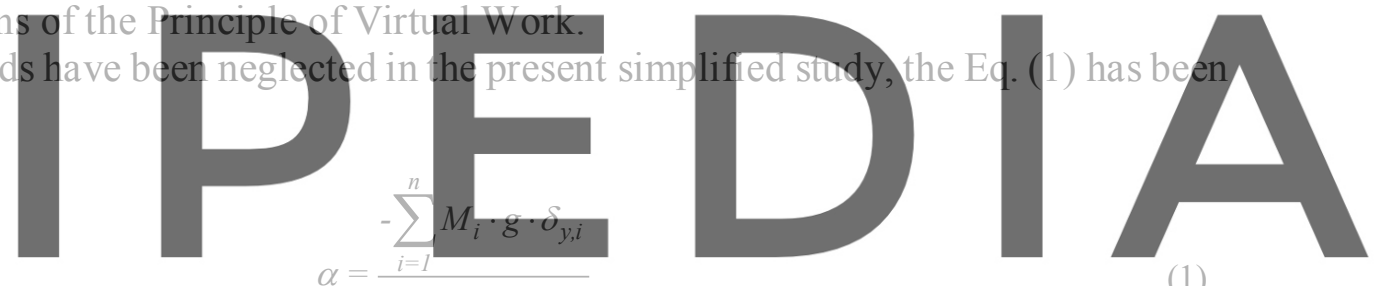

Register for free at https//www.scipedia.com to dióvinfload the version without the watermark

where: $g$ is the gravity acceleration, $n$ is the number of non-deformable blocks, $M_{i}$ is the mass of each block, $\delta_{y, i}$ and $\delta_{x, i}$ are the virtual vertical and horizontal displacements, respectively, evaluated in correspondence of the centroid of the $i^{t h}$ block.

According to the graphical method, the kinematic chain has been defined by imposing an infinitesimal rotation to the first rigid block.

\subsection{The collapse mechanisms definition}

Consistently with the theory of the limit analysis, the definition of the most likely kinematic chain should consist in an iterative procedure aimed at investigating each admissible block subdivision in order to identify the collapse mechanism that returns the minimum value of the load multiplier $\alpha$.

Such an approach would certainly provide a closed-form result, but it would involve an excessive computational effort, especially if referred to the diaphragm arches, for which both the position of the non-dissipative hinges and the direction of the possible cracks must be defined. 
From a mechanical point of view, the rigid-block subdivision corresponds to the definition of a crack pattern, whose development starts from the zones in which the tensile strength of the masonry is overcome toward the most compressed zones, considered as the possible positions of the hinges.

According to these assumptions, a suitable simplified procedure for the definition of the kinematic chain has been implemented and validated on the basis of studies found in literature, carried out on the Basilica of Santa Maria del Mar [SMM] in Barcelona. Such a procedure consists in step-by-step numerical analyses, in which the progressive cracking is introduced in the models by means of mesh subdivisions.

To this purpose, FEM Model of the diaphragm arches have been implemented in Midas Gen with a macro-modelling approach. Since the in-plane behaviour is investigated in this study, bidimensional elements with a conventional thickness of 1 meter have been assumed for the mesh. For the masonry material, an initial Elastic Modulus $E=8000 \mathrm{MPa}$, a Poisson's coefficient $v=0.3$ and a specific weight $\gamma=2200 \mathrm{~kg} / \mathrm{m}^{3}$ have been considered, according to the values adopted in literature [13] for [SMM]. Finally, the mesh discontinuities have been introduced in the models if the tensile strength (conventionally assumed equal to $0.4 \mathrm{MPa}$ ) has been overcome.

The boundary conditions imposed in the step-by-step procedure provides a complete DOF restriction for the base nodes, a vertical gravity acceleration and a uniform horizontal acceleration increasing up to the formation of a sufficient number of hinges.

In particular, the kinematic chain of Figure 3, defined through the formation of 10 nondissipative hinges located at the base of the plers and at the intradoses and extradoses of the
arches, alternatively, has been obtained according to the proposed methodology, returning a
horizontal load multiplier $\alpha=0.11 \mathrm{~g}$.
The defined collapse mechanism results in good agreement with the reference study [14])(as
shown in Figure $3 \mathrm{~b}$ ), proving the reliability of the approach, despite the adopted simplified assumptions. The procedure is validated by literature $[14,15]$ also in a quantitative point of

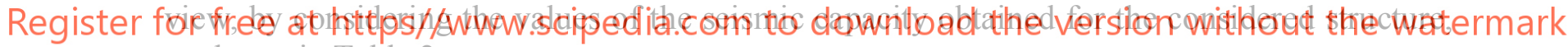
as shown in Table 2.

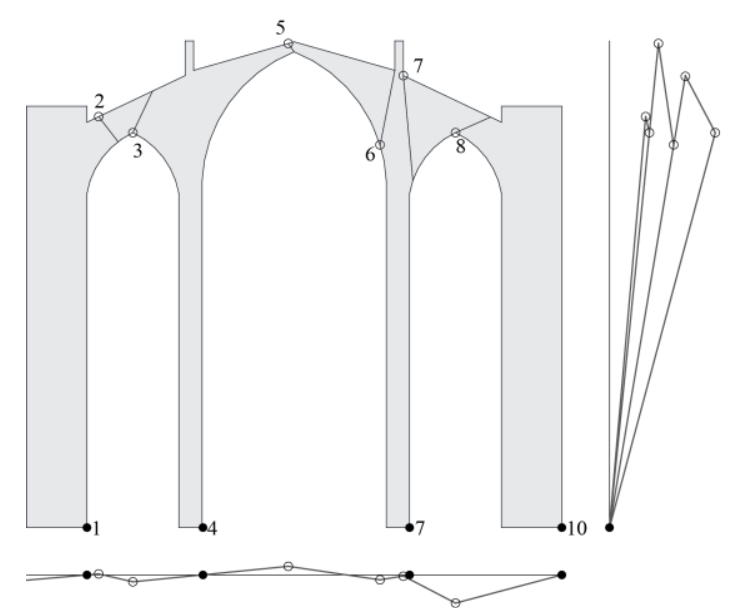

(a)

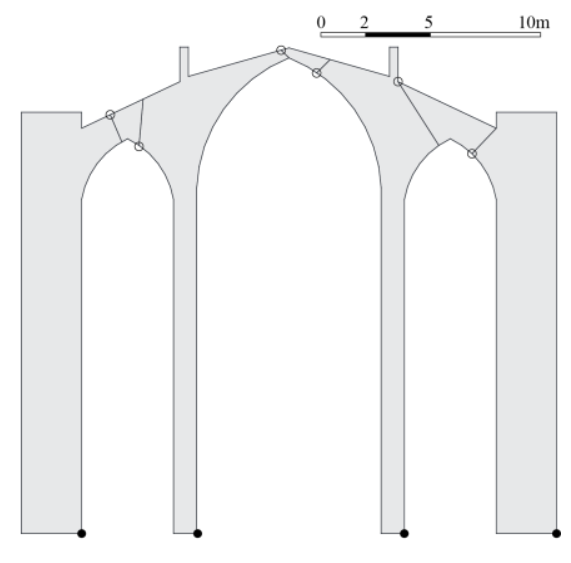

(b)

Figure 3: Collapse mechanism of the transversal arcade of [SMM]: (a) kinematic chain obtained in the current study and (b) collapse mechanism from Irizarry et al. (2003) [14] 
Table 2: Comparison of the horizontal load multipliers of the transversal arcade of [SMM]

\begin{tabular}{ccc}
\hline Reference & Type of analysis & $\boldsymbol{\alpha}$ [g] \\
\hline Current study & Limit analysis with a kinematic approach & 0.11 \\
\hline \multirow{2}{*}{ Irizarry et al. (2003) [14] } & FE Model & $0.13-0.14$ \\
& Limit analysis with a kinematic approach & $0.11-0.12$ \\
\hline \multirow{2}{*}{ Roca (2007) [15] } & Limit analysis with a static approach & 0.10 \\
& Limit analysis with a kinematic approach & 0.10 \\
\hline
\end{tabular}

\section{ANALYSIS OF CASE STUDIES}

\subsection{The kinematic analysis}

After having validated the proposed approach, it has been adopted for assessing the seismic capacity of the case studies [SMP], [SMG] and [SJB] introduced in section 2.

The kinematic chains and the collapse mechanisms obtained with the described procedure are shown in Figure 4.
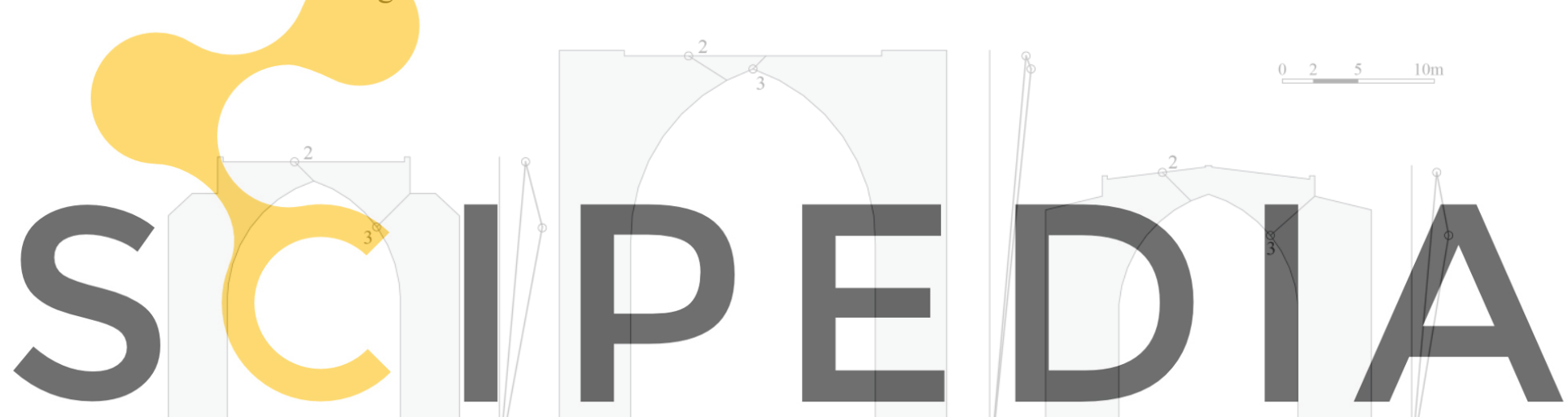

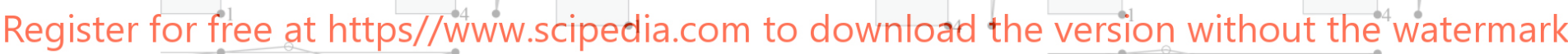

(a)

(b)

(c)

Figure 4: Collapse mechanisms and kinematic chains of the investigated case studies: (a) [SMP], (b) [SMG], (c) [SJB]

As it can be observed, all the investigated cases returned global collapse mechanisms, with the formation of two non-dissipative hinges placed at the base of each pier and two others hinges at the intrados and extrados of the arches, alternatively.

The horizontal load multipliers arisen from the limit analyses are as follows: $i$. [SMP]: $\alpha=0.215 ;$ ii. $[\mathrm{SMG}]: \alpha=0.162 ;$ iii. [SJB] $\alpha=0.277$.

The obtained horizontal accelerations are shown in Figure 5, where the results are provided as a function of the $h / h_{1}$ and $h / w$ ratios defined in section 2, with the linear trend curves.

In particular, in Figure 5b, the results obtained in De Matteis et al. 2019 [11] for the transversal arcades of some of the main European Gothic churches with a three-nave layout are also plotted. 


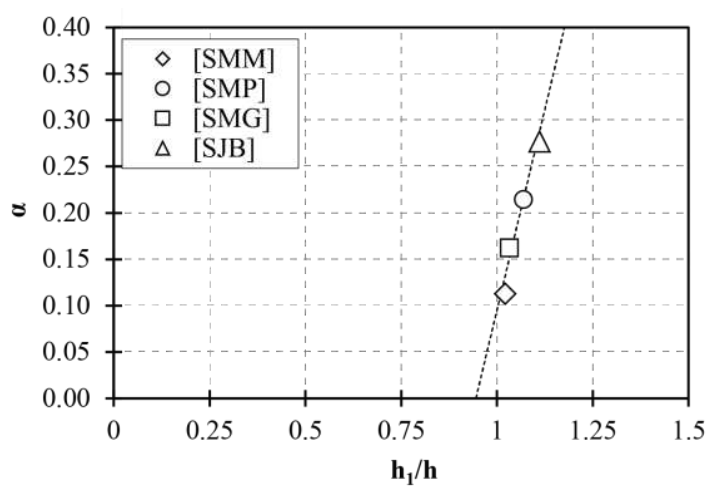

(a)

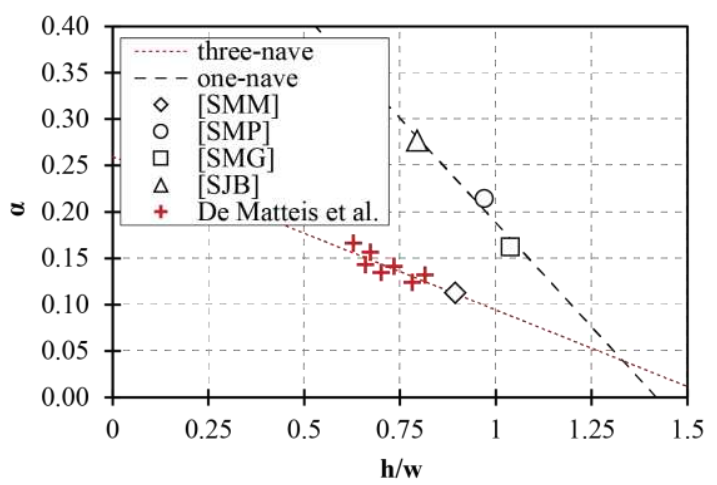

(b)

Figure 5: Results of the limit analyses in terms of (a) horizontal load multiplier $\alpha$ - diaphragmatic ratio $h_{l} / h$ and (b) horizontal load multiplier $\alpha$ - rising ratio $h / w$ (red points and line are referred to De Matteis et al. 2019 [11]).

The depicted results show a linear dependence between the seismic capacity of diaphragm arches and the $h_{1} / h$ ratio, which means that an increase in the capacity of the structures can be actually observed when the diaphragmatic system is used in churches.

As far as the rising ratio $h / w$ is concerned, it is worth noticing that the value obtained for the three-nave church of [SMM] appears to be consistent with the trend previously obtained in [11] for some Gothic transversal arcades. Moreover, the dependence of the seismic capacity from the $h / w$ ratio is confirmed by the cases with a one-nave layout, despite the different slope of the trend line.

Qualitatively, it coul strongly influenced by gives back a small value.
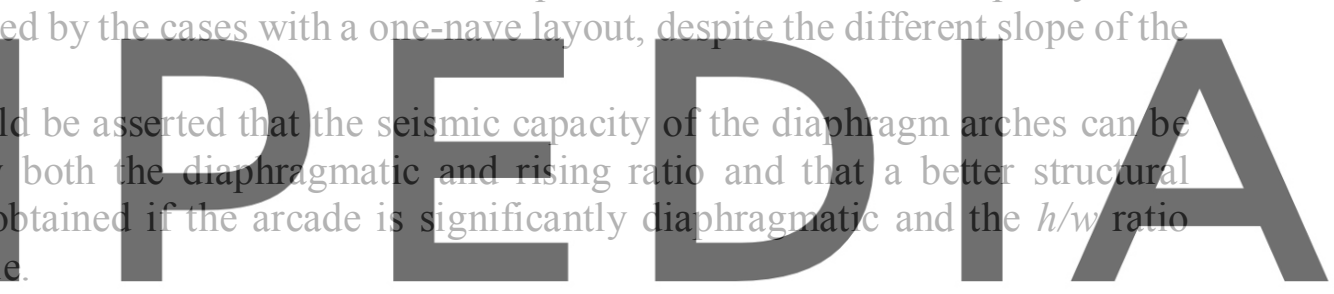

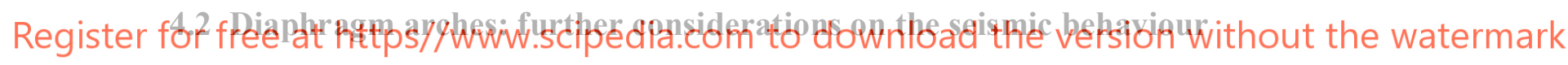

The seismic behaviour of the investigated diaphragm arches has been further assessed by means of additional analyses. In particular, starting from the original geometries of the considered cases, portions of masonry have been progressively removed in order to evaluate the beneficial contribution provided by each structural element on the seismic capacity.

Hence, the geometries of Figure 6 have been investigated, firstly by excluding portions of the lateral buttresses and then by removing the diaphragms.

It is worth mentioning that the portions of the buttresses not removed in the analyses correspond to the real height of the lateral chapels detected in the considered churches by the authors. Moreover, in order to determine the new geometrical configurations, the depths of the arches have been reduced, keeping constant the thickness, which has been obtained by positioning the key of the arch in correspondence of the maximum height of the original diaphragm. In case this value was not included in a thickness-to-span ratio ranging between $1 / 18$ and $1 / 10$, as retrieved from literature [12] and already investigated by the authors [16], it has been modified accordingly.

The modified configurations have been investigated by means of the procedure described and validated in the previous Section. 


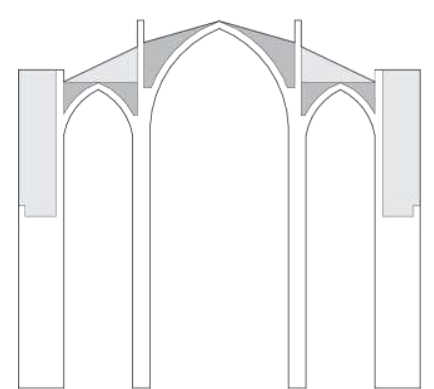

(a)

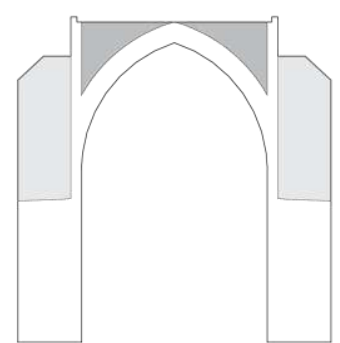

(b)

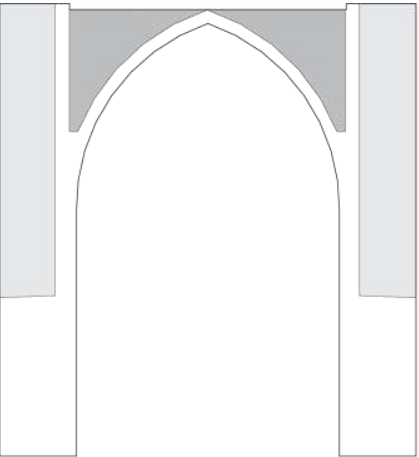

(c)

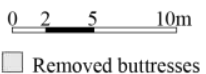

$\square$ Removed buttresses

$\square$ Removed diaphgram

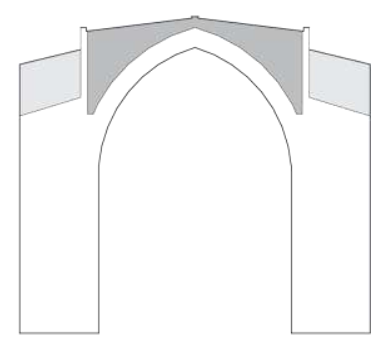

(d)

Figure 6: Investigated modified geometries: (a) [SMM], (b) [SMP], (c) [SMG) and (d) [SJB].

The results in terms of kinematic chains are shown in Figure 7 (a-h), while the obtained horizontal load multipliers are plotted in Figure $7 \mathrm{j}$ together with those arisen from the original geometries. The results are also summarized in Table 3.

The new limit analyses returned, for almost all the cases, local collapse mechanisms with the hinges occurring only in the thickness of the arches. The only exception is [SJB], whose modified geometries exhibited a global and a semi-global mechanism for the case without buttresses and without buttresses and diaphragm, respectively.

Moreover, the progressive removals of masonry portions from the original geometry have produced a strong decreasing of the seismic capacity of the transversal arcades in [SMM], [SMP] and affected by the absence of the original geometry of the arcade, in to the small size of the removed portions. Furthermore, the values of the geometric

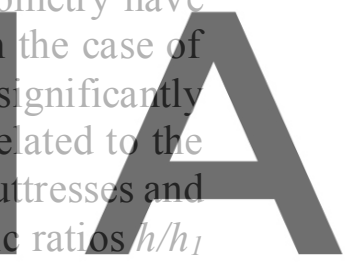
and $h / w$ reported in Table 1 and Figure 1 show that $[\mathrm{SJB}]$ is characterized by proportions that

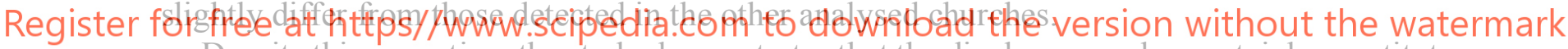
Despite this exception, the study demonstrates that the diaphragm arches certainly constitute a significant resource, in terms of structural capacity, for the churches and that both the diaphragms and the lateral buttresses can significantly improve the seismic behaviour of this kind of structural skeleton.

Table 3: Results of the limit analyses with the kinematic approach

\begin{tabular}{ccccc}
\hline Analysis & [SMM] & [SMP] & [SMG] & [SJB] \\
\hline Original Geometry & 0.113 & 0.215 & 0.162 & 0.277 \\
\hline No Buttresses & 0.048 & 0.070 & 0.070 & 0.312 \\
\hline No Diaphragm & 0.043 & 0.034 & 0.061 & 0.285 \\
\hline
\end{tabular}




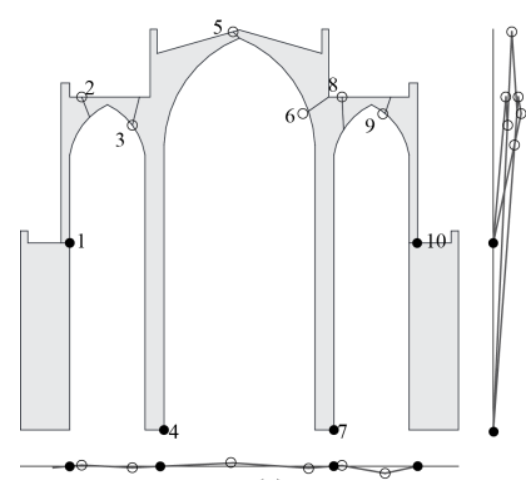

(a)
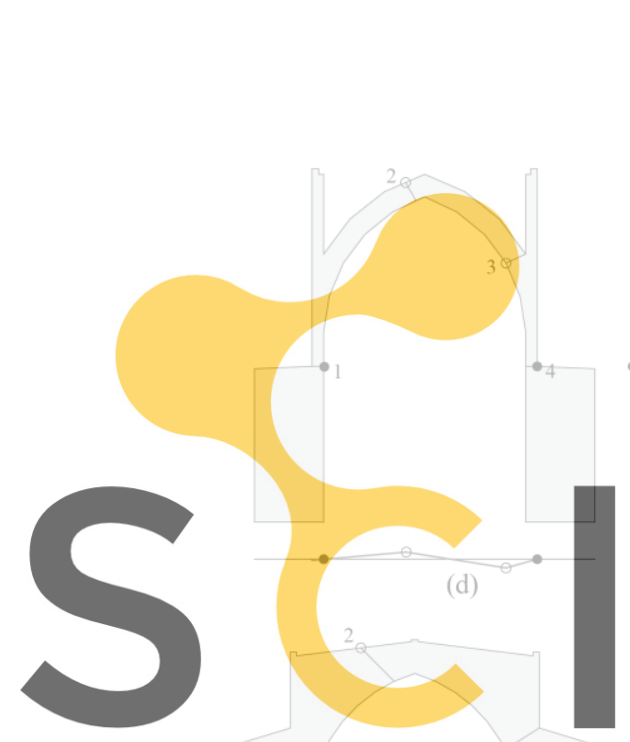

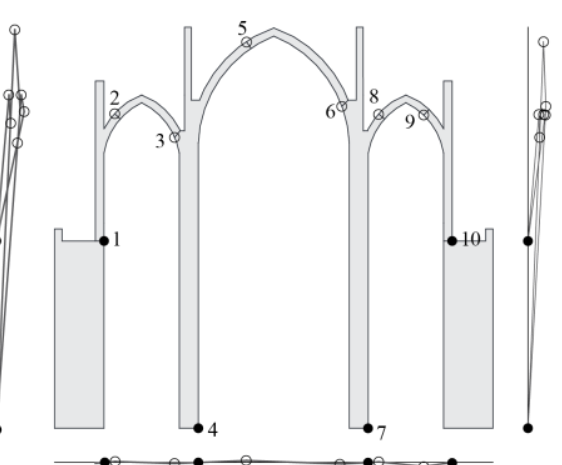

(b)

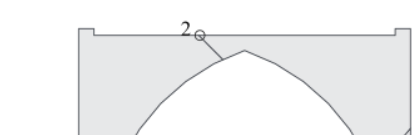

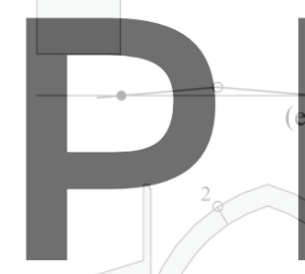

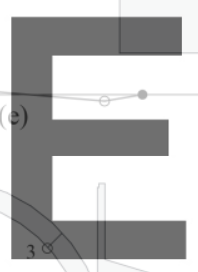

Register for free at https//www.scipedia.com to download

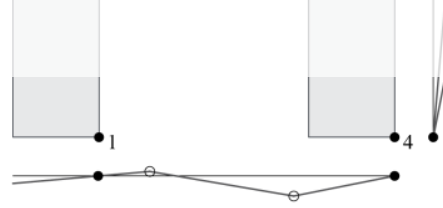

(g)

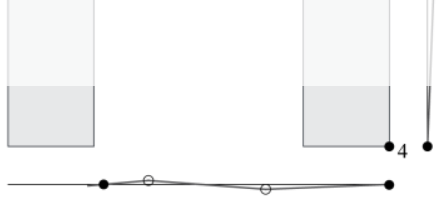

(h)

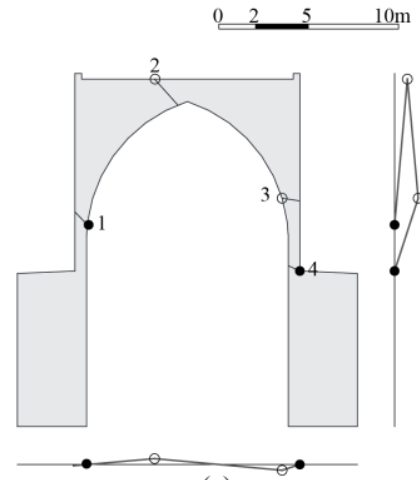

(c)

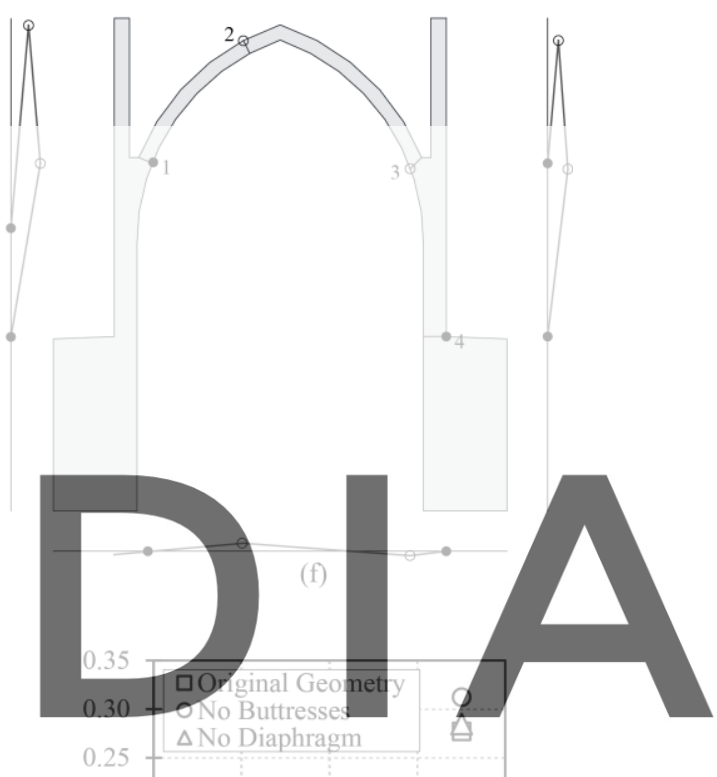

Figure 7: Kinematic chains for the modified geometries: (a) [SMM] without buttresses and (b) without diaphragms; (c) [SMP] without buttresses and (d) without diaphragms; (e) [SMG] without buttresses and (f) without diaphragms; (g) [SJB] without buttresses and (h) without diaphragms. (j) Obtained horizontal load multipliers

\section{CONCLUSIONS}

In this study, the seismic behaviour of diaphragm arches has been investigated by means of an integrated numerical-analytical approach, which has been validated on the basis of studies carried out in literature on the Basilica of Santa Maria del Mar [SMM] in Barcelona.

In particular, geometries derived from real examples of the Catalan Gothic architecture have been adopted to define simplified FEM Models aimed at identifying the possible position of the 
hinges and the collapse mechanisms for each analysed case.

Then, in order to prove the seismic capacity of the diaphragmatic system, limit analyses with a kinematic approach have been implemented for the detected arcades, considered both in their original and modified geometries.

Specific geometric coefficients have been identified in order to investigate the influence of the geometry on the global behaviour of this skeleton, finding an effective incidence of the diaphragmatic $\left(h / h_{1}\right)$ and rising $(h / w)$ ratios on the seismic capacity of the investigated structures. Furthermore, since in almost all cases the modified geometries demonstrated a worse seismic capacity, the study revealed the structural influence of the removed structural elements on the global behaviour of the original arcades.

In general, the present study clearly demonstrates that an increase of the structural capacity can actually be observed when diaphragmatic systems are introduced in churches.

Acknowledgements. The present study has been developed as part of a scholarship funded in the framework of the National Operational Program ESF-ESFR Research and Innovation (PON RI 2014-2020), Action I.1 related to Innovative Industrial Ph.D (Project Code - CUP B29D17001610006).

\section{REFERENCES}

[1] Vivian, P. The Beginnings of Gothic Architecture in Languedoc. The Art Bulletin. (1988). 70. 104. 10.2307/3051156.

[2] De Matteis, G. \& Mazzolani, F.M. 2010. The Fossanova church: seismic vulnerability assessment by numerical and physical testing. International Journal of Architec-tural Heritage, 4: 222-245.

[3] Roca, P., Pellegrini, L., Oñate, E., Hanganu, A. Analysis of the structure of Gothic Cathedrals. Application to Barcelona Cathedral. In Structural Analysis of Historical Contruction II. Possibilities of Numerical and Experimental Techniques, Roca et al. (Eds.), CIMNE, Barcelona, (1998).

[4] Roca, P. Studies on the structure of Gothic Cathedrals. In Historical Constructions. P. B. Lourenço and P. Roca (Eds.), University of Guimaraes, Guimaraes, (2001).

[5] Zaragozá Catalán, A. (1990). Iglesias de arcos diafragma y armadura de madera en la arquitectura medieval valenciana. Valencia: Universidad Politécnica de Valencia.

[6] Roca, P., Cervera, M., Pelà, L., Clemente, R., Chiumenti, M. Continuum FE Models for the Analysis of Mallorca Cathedral. Engineering Structures, (2013) 46: 653-670, doi: http://dx.doi.org/10.1016/j.engstruct.2012.08.005.

[7] Pulido, V., Alonso-Durá, A., Fenollosa, E., Boquera, A. Análisis constructivo y estructural de la catedral de Valencia. Informes de la Construcción (2016) 68, 543, e158, 10.3989/ic.15.102.

[8] Cassinello, P. Influencia de los terremotos históricos en la construcción de las catedrales góticas españolas. Annali Di Architettura: Rivista del centro Internazionale di Studi di Architettura "Andrea Palladio" (2005) 17: 9-20.

[9] Lavedan, P., L'Architecture gothique religieuse en Catalogne, Valence et Baléars. Laurens, Paris, 1935

[10] Durliat, M., L'art dans le Royaume de Majorque. Éd. Privat, Toulouse

[11] De Matteis, G., Cacace, D., Rouhi, J., Zizi, M. Seismic behaviour of Gothic transversal 
arcades: A preliminary parametric investigation. In Proceedings of SEMC2019, Advances in Engineering Materials, Structures and Systems: Innovations, Mechanics and Applications. (2019) Cape Town, South Africa. ISBN:978-1-138-38696-9.

[12] Heyman, J. The Stone Skeleton: Structural Engineering of Masonry Architecture. (1995) Cambridge University Press.

[13] Murcia-Delso, J., Das, A. K., Roca, P., Cervera, M. Seismic safety analysis of historical masonry structures using a damage constitutive model. In COMPDYN 2009 - ECCOMAS Thematic Conference on Computational Methods in Structural Dynamics and Earthquake Engineering. M. Papadrakakis, N.D. Lagaros, M. Fragiadakis (Eds.), Rhodes, Greece (2009).

[14] Irizarry, J., Podestà, S., Resemini, S. Curvas de capacidad para edificios monumentales: la iglesia Santa María del Mar de Barcelona. In proceedings of $2^{\circ}$ Congreso Nacional de Ingeniería Sísmica. $1^{\text {st }} 4^{\text {th }}$ April, Malaga, Spain. (2003).

[15] Roca,P. Basílica de Santa Maria del Mar: estudi de l'estructura. Technical University of Catalonia (2007).

[16] Cacace, D., Rouhi, J., Zizi, M. and De Matteis, G. (2019). Vulnerabilità sismica di archi in muratura: uno studio parametrico con approccio cinematico. XVIII Convegno ANIDIS L’Ingegneria sismica in Italia. Sep. 15-19. Ascoli Piceno, Italy. 